\title{
Analyzing the Factors of Job Satisfaction in a Mexican Hospital with Binary Indicators by Confirmatory Factor Analysis
}

\author{
Kismiantini ${ }^{1}$, Osval Antonio Montesinos López ${ }^{2}$, García Martínez J. Jesús ${ }^{2} \&$ Franco Pérez Emeterio ${ }^{2}$ \\ ${ }^{1}$ Yogyakarta State University, Yogyakarta, Indonesia \\ ${ }^{2}$ Universidad de Colima, Colima, México \\ Correspondence: Osval Antonio Montesinos López, Universidad de Colima, Colima, México. E-mail: \\ oamontes2@hotmail.com
}

Received: June 3, 2014

Accepted: June 22, 2014

Online Published: July 25, 2014

doi:10.5539/ijbm.v9n8p61

URL: http://dx.doi.org/10.5539/ijbm.v9n8p61

\begin{abstract}
The Mexican Social Security Institute (IMSS) belongs to the Mexican health sector and provide health services to beneficiaries, employers, pensioners and retirees across Mexico. However, there are evidences that beneficiaries are not satisfied with the health services they receive. For this reason, with a sample of 417 out of 669 workers of the General Hospital number 1, located in the State of Colima, Mexico, was conducted this research to measure the level of satisfaction of IMSS workers, the factors underlying this satisfaction and to propose an instrument to measure job satisfaction in this Mexican institution with the purpose to generate efficient management models for workers that can help to improve the client satisfaction levels. Using Confirmatory Factor Analysis (CFA) was confirmed an instrument of 21 items and five factors (personal development, interpersonal relationship, recognition, work nature, and work environments) to measure job satisfaction in a Mexican hospital and also we shown evidence that the same construct is appropriate for both genders with the exception that female presented higher levels of satisfaction in their job for the personal development.
\end{abstract}

Keywords: job satisfaction, health sector, instrument, Confirmatory Factor Analysis, gender

\section{Introduction}

The Mexican Social Security Institute (IMSS) belongs to the Mexican health sector, and it was born on January 19, 1943 (Mexican Institute of Social Security, 2012a \& 2012b), with the main goal of providing quality of health services to beneficiaries, employers, pensioners and retirees. This goal is challenging because in 2011 the IMSS had 431,518 employees (doctors, nurses and administrative staff) and need to attend 59,906,396 beneficiaries across Mexico. This involves the consolidation of a service model designed from the perspective of user satisfaction and their appropriate diagnostic and therapeutic needs, not only from elementary compliance of the protocols and operational processes. To achieve this goal, it is important that the doctor and staff are satisfied with the work they do every day, which will result in satisfaction of the beneficiaries (Mexican Institute of Social Security, 2011).

The IMSS is an extremely important institution for Mexico. However, there are many evidences reported in local newspapers, television and scientific papers (Infante, 2006; González, 2011; Sutton et al., 2013; Rodríguez, 2013; Godínez, 2014) that beneficiaries are not satisfied with the services received, the shortage of medicines and the discriminatory treatment of people. For these reasons, the administrators of first level of the IMSS have a great concern for this problem. Therefore, it is important to know the level of satisfaction of the employees of the IMSS, the factors underlying this satisfaction and to propose an instrument to measure job satisfaction in this Mexican institution with the purpose to generate efficient management models for workers that can help to improve the client satisfaction levels.

Job satisfaction is a sophisticated topic for many researchers. Spector (1997) defined job satisfaction simply as how people feel about their jobs whether they are satisfied or dissatisfied. Many researchers have attempted to identify the various factors which affecting the job satisfaction. Process of selecting factors has been done by looking through the existence of variables on the data and literature review. Based on those, there are five factors to be used on this study. The first factor is personal development. Maslow (1970) suggests that personal 
development occurs through process of self-actualization. The self-actualization would be activities to improve ability and skills through training, apply own ideas in work, promote higher position, and enhance quality of work. Second factor is interpersonal relationships. Donovan et al (1998) stated that job satisfaction is related to interpersonal relationships such as support, teamwork, and positive treatment from coworkers and supervisors. Third factor is recognition. Danis and Usman (2010) mentioned that recognition is related to how the work of an employee is evaluated and how much appreciation he receives in return from organization. Fourth factor is work nature. The work nature such as work load, work speed, and monotonous activities can influence on the employees' performance (Bosh, 2011). Fifth factor is work environments. Lang (2005) reports that when the office temperature increased from 68 to 77 degrees Farenheit, there were significant reduction of worker's typing errors and enlargement of the worker's output. Based on the five factors of job satisfaction above, we can develop a model using a confirmatory factor analysis. A confirmatory factor analysis (CFA) is a statistical technique used to verify the factor structure or the latent construct of a set of observed variables or indicators.

In the job satisfaction paradox, Kaiser (2002) and Bender et al (2005) outline that female workers report higher job satisfaction than male regardless of disadvantaged position in terms of earnings, recruitment, promotions and career prospects. Hence, the gender differences are important in the model. In the Structural Equation Model (SEM) context, multiple groups and multiple indicators and multiple causes(MIMIC)are two models which cover the gender differences. The objectives of this project are to investigate the five factors (personal development, interpersonal relationship, recognition, work nature, and work environments) of job satisfaction, and to compare models between two groups (female and male).

\section{Data and Methods}

\subsection{Data}

In 2011, the IMSS at the national level had 431, 518 employees, of which 3,550 correspond to the state of Colima (Mexican Institute of Social Security, 2012a \& 2012b). This research was conducted at the General Hospital number 1, located in the State of Colima, Mexico, with a population in 2011 of 669 workers. The sample used in this study was four hundreds and seventeen employees of this hospital and to them we apply a job satisfaction survey. The survey was applied for the two last authors or the present research. The sample is composed of 87 doctors, 144 nurses and 186 administrative staff. The respondents were 226 female and 191 male employees. Twenty one indicators and five latent factors have been used in this project. See Table 1 for the dimensions and items in the job satisfaction study.

Table 1. Job satisfaction dimensions and items

\begin{tabular}{lll}
\hline \multicolumn{1}{c}{ Latent Factors } & Observed Variable & Statement \\
\hline Personal & Promot & I have an opportunity to be promoted \\
Development & Qualiwrk & I am satisfied with the quality of work \\
(PD) & Training & I am satisfied with training \\
& Ideas & I am pleased that my ideas are considered too \\
Interpersonal & Cowrks & I am satisfied with interpersonal relationship with colleagues \\
Relationship & Teamwrk & I am satisfied working in teamwork \\
(IR) & Boss & I am satisfied with interpersonal relationship with my immediate boss \\
& Equaltrt & I am receiving equal treatment \\
& Commun & I am satisfied with communication with my immediate boss \\
Recognition & Salary & I am satisfied with salary \\
(RE) & Bonus & When I do a good job I receive the bonus \\
& Accomp & I am satisfied with accomplishment \\
& Steadyemp & I am satisfied with employment stability \\
Work Nature & Wrkamont & I am satisfied with work amount \\
(WN) & Wrksped & I am satisfied with work speed \\
& Monoton & The work I do is monotonous \\
Work Environment & Cleanhy & My work space is clean and hygiene \\
(WE) & Light & My work space is light \\
& Venti & My work space have ventilation \\
& Temp & My work space have temperature regulation \\
& Workspace & I am satisfied with my work space \\
\hline
\end{tabular}


All indicators were measured on a 2-point scale with 0 refers to dissatisfied and 1 refers to satisfied. Gender was coded by 0 as male and 1 as female. Therefore, analysis has been done through categorical approach. Importantly, on the one hand that this proposed instrument is different to the Job Diagnostic Survey (JDS) proposed by Hackman \& Oldham, 1975) that measures only perceived characteristics of jobs with six core job dimensions (skill variety, task identity, task significance, autonomy, feedback from job, feedback from agents) and the composite motivational potential score (Spector, 1985) on a seven point Likert scale. Although in general the proposed instrument is different to the JDS proposed by Hackman \& Oldham (1975) the items in our instrument corresponding to the dimension work nature are related to the perceived characteristics of jobs. On the other hand, our instrument is very close to the proposed by Spector (1985) that measures the human service staff satisfaction in a six point Liker scale. This instrument is a nine-dimension measure (pay, promotion, supervision, benefits, contingent rewards, operating procedures, co-workers, nature of work and communications) of employee job satisfaction applicable specifically to job satisfaction to human service, public and nonprofit sector organizations. Although our instrument has 5 dimensions it is really important to point out that the PD dimension in our instrument cover items related to supervision, promotion and benefits of the Spector (1985) instrument. The IR dimension contains items related to co-workers and communications. The RE dimension cover items of satisfaction with pay and contingent rewards. Work nature dimension is the same as that of Spector (1985) and finally the WE dimension in our instrument is related to work conditions (physical conditions), but Spector (1985) only take into account the operational conditions (such as rules, procedures and red tape).

\subsection{Analysis}

CFA is a statistical technique used to evaluate the measurement models that represent hypotheses about relations between indicators and factors (Kline, 2011). The factors or latent constructs are assumed to cause the observed scores in the indicators. In the Structural Equation Models (SEM) approach, multiple groups and Multiple Indicators and Multiple Causes (MIMIC) models are useful to examine models between two or more groups. In this project, gender ( 0 : males, 1 : females) is a grouping variable.

Multiple groups analysis is a technique to examine a well specified model in two or more groups (e.g. males versus females) and to test if the loading, covariances, etc are different or not across groups. To assess group differences in latent means, the structure underlying the dependent measures must be similar across groups. The steps in the multiple groups analysis are verifying measurement invariance. The following tests of measurement invariance were performed: configural invariance, loading and intercept/threshold invariance, error (co) variance invariance. MIMIC analysis is used to test the impact of a covariate on a measurement model with both cause indicators and effects indicators (MacCallum \& Browne, 1993). In the MIMIC model, categorical indicator performs group membership.

In CFA a model fit can be tested using Chi-Square. A non-signicant Chi-Square is indication of good fit. However, the Chi-Square test is more sensitive as a larger sample size. Hence, Hu and Bentler recommend to report two or three additional indices (Hu \& Bentler, 1999), such as Comparative Fit Index (CFI), Root Mean Square Error of Approximation (RMSEA), Standardized Root Mean Square Residual (SRMR). For the categorical data, Yu and Muthén (2002) recommended Weighted Root Mean Square (WRMR) instead of the SRMR. The CFI evaluates the fit of the model relative to another baseline model. Better fits are indicated by higher values to a maximum of 1 , which is $\geq 0.96$ when sample size $\geq 250$ (Yu, 2002). The RMSEA gives lack of fit in a model compared to a perfect model. A value below 0.06 for RMSEA gives acceptable model (Browne \& Cudeck, 1993). The WRMR assesses average weighted residuals, which ranging from 0-1. Yu and Muthén (2002) suggests that a cutoff of $\leq 1.0$ (close to 1.0) for the weighted root mean square residual (WRMR) can be used for models with binary outcomes when sample size $\geq 250$.

\section{Results and Discussions}

Table 2 provided the proportions and counts for the indicators. As can be seen from Table 2, the proportions for each indicator were relatively similar across gender. Higher proportions $(\geq 0.76)$ found in the indicators for the PD, IR, and RE factors. Low proportions $(0.25-0.50)$ found in the indicators for the WE. The only factor which had three categories the strength of proportions (high, medium (0.51-0.75), low) was WN factor. 
Table 2. Proportions and counts for categorical variables

\begin{tabular}{|c|c|c|c|c|c|c|c|c|c|}
\hline \multirow{3}{*}{ Indicator } & \multirow{3}{*}{ Factor } & \multicolumn{4}{|l|}{ Male } & \multicolumn{4}{|l|}{ Female } \\
\hline & & \multicolumn{2}{|l|}{ Dissatified } & \multicolumn{2}{|l|}{ Satisfied } & \multicolumn{2}{|l|}{ Dissatified } & \multicolumn{2}{|l|}{ Satisfied } \\
\hline & & Proportion & Count & Proportion & Count & Proportion & Count & Proportion & Count \\
\hline Promot & \multirow{5}{*}{$\mathrm{PD}$} & 0.188 & 36 & 0.812 & 155 & 0.128 & 29 & 0.872 & 197 \\
\hline Qualiwrk & & 0.209 & 40 & 0.791 & 151 & 0.115 & 26 & 0.885 & 200 \\
\hline Training & & 0.445 & 85 & 0.555 & 106 & 0.323 & 73 & 0.677 & 153 \\
\hline Ideas & & 0.361 & 69 & 0.639 & 122 & 0.316 & 71 & 0.684 & 154 \\
\hline Cowrks & & 0.079 & 15 & 0.921 & 176 & 0.088 & 20 & 0.912 & 206 \\
\hline Teamwrk & \multirow{4}{*}{ IR } & 0.251 & 48 & 0.749 & 143 & 0.341 & 77 & 0.659 & 149 \\
\hline Boss & & 0.225 & 43 & 0.775 & 148 & 0.235 & 53 & 0.765 & 173 \\
\hline Equaltrt & & 0.178 & 34 & 0.822 & 157 & 0.181 & 41 & 0.819 & 185 \\
\hline Commun & & 0.188 & 36 & 0.812 & 155 & 0.199 & 45 & 0.801 & 181 \\
\hline Salary & \multirow{4}{*}{$\mathrm{RE}$} & 0.398 & 76 & 0.602 & 115 & 0.292 & 66 & 0.708 & 160 \\
\hline Bonus & & 0.168 & 32 & 0.832 & 159 & 0.106 & 24 & 0.894 & 202 \\
\hline Accomp & & 0.110 & 21 & 0.890 & 170 & 0.084 & 19 & 0.916 & 207 \\
\hline Steadyem & & 0.073 & 14 & 0.927 & 177 & 0.102 & 23 & 0.898 & 203 \\
\hline Wrkamont & \multirow{3}{*}{$\mathrm{WN}$} & 0.272 & 52 & 0.728 & 139 & 0.407 & 92 & 0.593 & 134 \\
\hline Wrksped & & 0.246 & 47 & 0.754 & 144 & 0.239 & 54 & 0.761 & 172 \\
\hline Monoton & & 0.780 & 149 & 0.220 & 42 & 0.783 & 177 & 0.217 & 49 \\
\hline Cleanhy & \multirow{5}{*}{ WE } & 0.529 & 101 & 0.471 & 90 & 0.580 & 131 & 0.420 & 95 \\
\hline Light & & 0.272 & 52 & 0.728 & 139 & 0.363 & 82 & 0.637 & 144 \\
\hline Venti & & 0.476 & 91 & 0.524 & 100 & 0.522 & 118 & 0.478 & 108 \\
\hline Temp & & 0.518 & 99 & 0.482 & 92 & 0.553 & 125 & 0.447 & 101 \\
\hline Workspace & & 0.476 & 91 & 0.524 & 100 & 0.593 & 134 & 0.407 & 92 \\
\hline
\end{tabular}

Figure 1 showed the relationship between indicators and factors through confirmatory factor analysis model. The first loading of each factor has been fixed at 1 for identification. This model also allows correlated factors. Ten correlations or covariances were established since there were five factors. This model was over identified since the number of observations was greater than the number of parameters. Twenty one indicators yielded $21(21+1) / 2=231$ number of observations. There was 52 parameters (16 loadings, 5 factor variances, 21 thresholds, 10 covariances between factors) to be estimated so the degrees of freedom for testing this model was 179. When the variables are categorical, thresholds are necessary to get the estimates for classifying the responses and only one threshold for each binary variable is enough. 


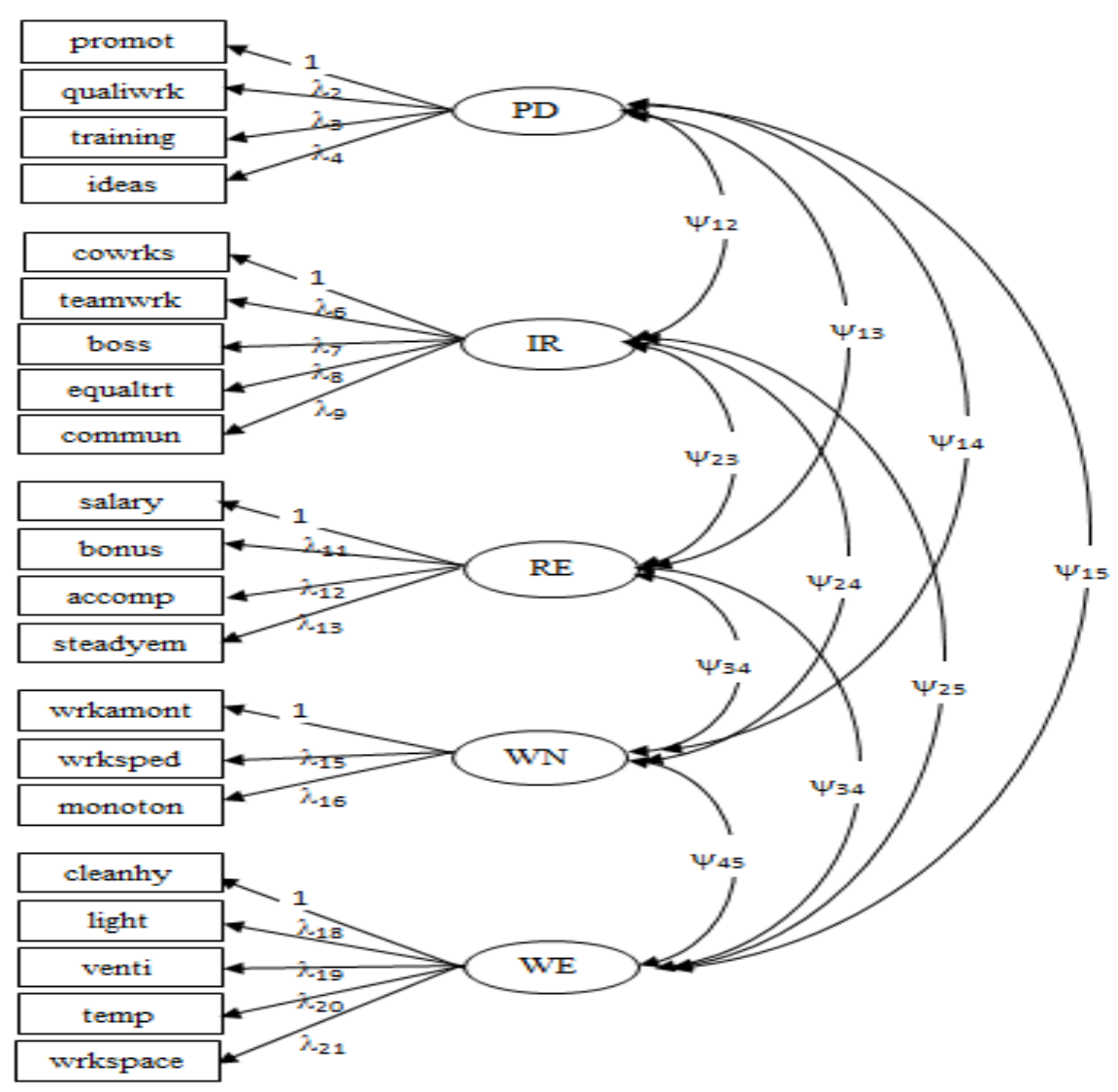

Figure 1. A path diagram of CFA representing the factors structure of the job satisfaction

\subsection{Confirmatory Factor Analysis}

CFA was accomplished to construct measurement model. Since the latent factors of job satisfaction are continuous variables and theindicators are categorical variables, thus thisCFAis also known as item response theory. The data was fitted by two parameter logistic for binary responses using weighted least squares means and variance adjusted (WLSMV) estimation with probit link. The overall fit of the model was good, $\chi_{(179)}^{2}=$ 276.782, $p<0.0001$, the RMSEA was $0.036<0.06$, the CFI was $0.971>0.96$, and the WRMR was 1.001 close to 1 .

Table 3. Estimates for the CFA model of the job satisfaction

\begin{tabular}{|c|c|c|c|c|c|}
\hline Indicator & Factor & $\begin{array}{l}\text { Standardized } \\
\text { Estimate }\end{array}$ & $\begin{array}{l}\text { Unstandardized } \\
\text { Estimate }\end{array}$ & $\begin{array}{l}\text { Unstandardized } \\
\text { S.E. }\end{array}$ & $\begin{array}{l}\text { Unstandardized } \\
p \text {-value }\end{array}$ \\
\hline Promot & \multirow{4}{*}{ PD } & 0.719 & 1.000 & - & - \\
\hline Qualiwrk & & 0.626 & 0.775 & 0.175 & $<0.001$ \\
\hline Training & & 0.721 & 1.004 & 0.238 & $<0.001$ \\
\hline Ideas & & 0.815 & 1.358 & 0.373 & $<0.001$ \\
\hline Cowrks & \multirow{5}{*}{ IR } & 0.495 & 1.000 & - & - \\
\hline Teamwrk & & 0.610 & 1.350 & 0.375 & $<0.001$ \\
\hline Boss & & 0.919 & 4.090 & 1.293 & 0.002 \\
\hline Equaltrt & & 0.872 & 3.120 & 0.904 & 0.001 \\
\hline Commun & & 0.882 & 3.282 & 0.992 & 0.001 \\
\hline Salary & \multirow{4}{*}{$\mathrm{RE}$} & 0.840 & 1.000 & - & - \\
\hline Bonus & & 0.666 & 0.577 & 0.186 & 0.002 \\
\hline Accomp & & 0.835 & 0.978 & 0.412 & 0.018 \\
\hline Steadyem & & 0.699 & 0.631 & 0.217 & 0.004 \\
\hline
\end{tabular}




\begin{tabular}{|c|c|c|c|c|c|}
\hline Wrkamont & & 0.884 & 1.000 & - & - \\
\hline Wrksped & WN & 0.869 & 0.927 & 0.483 & 0.055 \\
\hline Monoton & & -0.208 & -0.112 & 0.069 & 0.103 \\
\hline Cleanhy & & 0.695 & 1.000 & - & - \\
\hline Light & & 0.755 & 1.191 & 0.216 & $<0.001$ \\
\hline Venti & WE & 0.960 & 3.566 & 1.082 & 0.001 \\
\hline Temp & & 0.889 & 2.011 & 0.394 & $<0.001$ \\
\hline Workspace & & 0.735 & 1.122 & 0.186 & $<0.001$ \\
\hline
\end{tabular}

The correlation between PD and IR was estimated at 0.654 , between PD and RE at 0.611 , between PD and WN at 0.500 , and between PD and WE at 0.524 . The correlation between IR and RE was estimated at 0.455 , between IR and WN at 0.356 , between IR and WE at 0.382 . The correlation between RE and WN was estimated at 0.372 , and between RE and WE at 0.382 . The correlation between WN and WE was estimated at 0.426 . The factor loadings for each indicator are shown in Table 3. All indicators of PD, IR, RE, and WE were statistically significant at the level 0.05 and none indicators of WN were significant at the level 0.05 .

\subsection{Multiple Groups}

Since female workers were reported to have higher job satisfaction than male thus comparing different gender on the job satisfaction is important. For fitting data using multiple groups as shown in Figure 2, ideally sample size should be the same in each group. In this project, the number of females is 226 and males is 191. These two sample sizes are almost equal. The multiple groups analysis has been done by several process of measurement invariance [configural invariance, loading and intercept/threshold invariance, error (co)variance invariance]. Structural invariance in the latent variance and latent mean are meaningful to compare factor variance and factor means across groups.
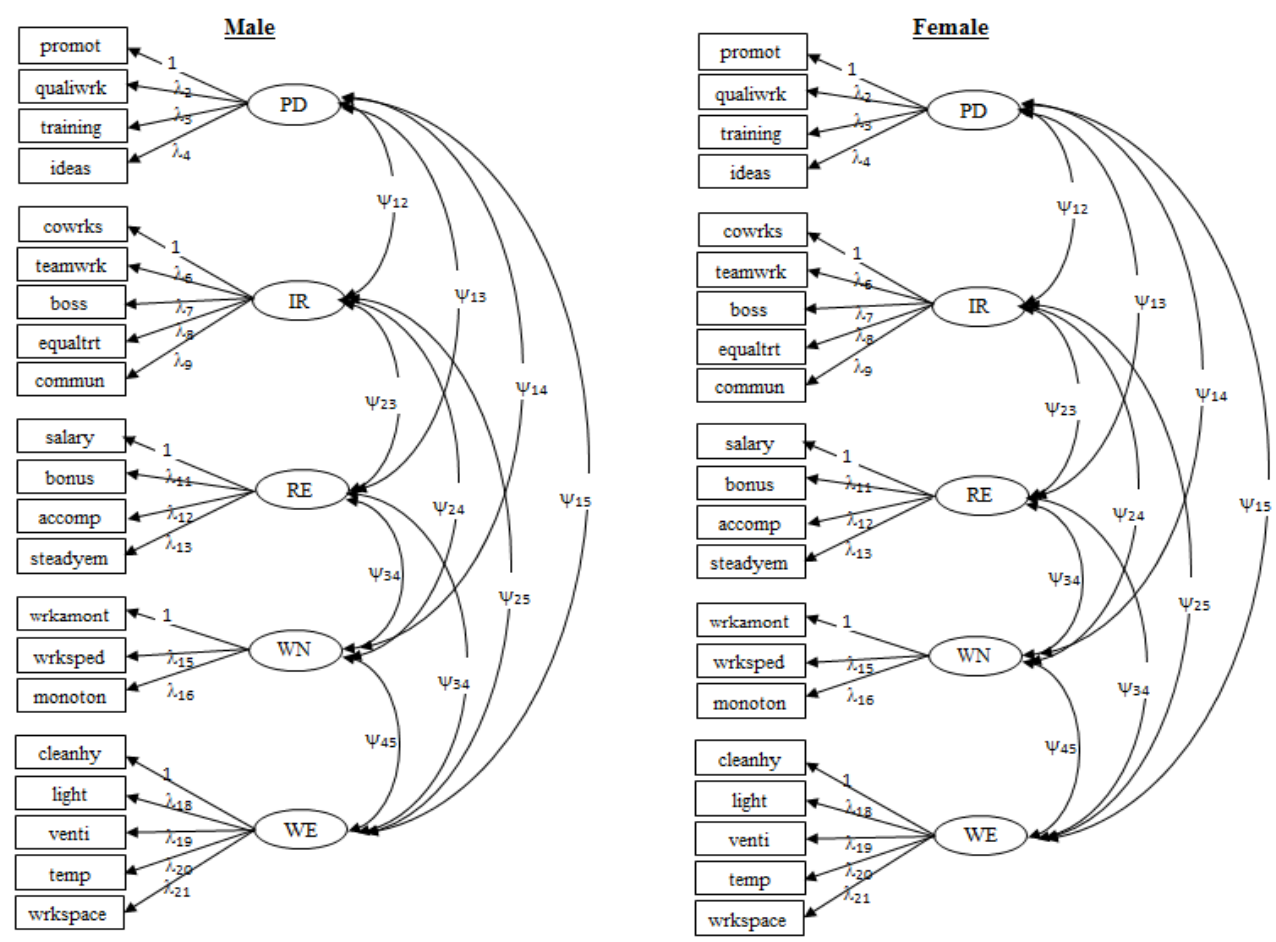

Figure 2. A path diagram of two groups (male and female) representing the factor structure of the job satisfaction

\subsubsection{Configural Invariance}

Configural invariance was evaluated by estimating the unconstrained measurement model separately for males and females. Based on the Figure 1, the latent factors were identified by fixing the first factor loading at 1 and the latent factor intercepts at 0 . In addition, it was necessary to fix all residual variances of the indicators at 1 in 
the measurement model with WLSMV estimation. The overall model fit for the test of configural invariance is shown in Table 4. The chi-square was significant, which suggested a lack of exact model fit across gender groups [the chi-square contribution for males (225.529) and female (226.650) are approximately equal]. Other fit indices showed that the model has a good fit. The CFI of 0.970 exceeded 0.96 , RMSEA of 0.036 was below 0.06 , and WRMR of 1.268 was close to 1 . The results obtained shows that the same factors structure holds for males and females.

\subsubsection{Loading and Intercept/Treshold Invariance}

Since there is evidence of configural invariance, the evaluation can be continued to test loading and intercept/treshold invariance. For categorical measurement models, loadings and tresholds are often constrained simultaneously. The reason is that both item parameters (loading and threshold) influence the item probability function, so both parameters must be invariant in order to make meaningful structural level-comparison across groups (Bovaird \& Koziol, 2012). The chi-square difference test for the measurement model was not significant $\left(\Delta \chi_{(11)}^{2}=14.736, p=0.195\right)$ as shown in Table 4. This indicates that the factor loadings and intercepts/tresholds of the job satisfaction are invariant across gender. In other words, the metric and the strong factorial invariances hold for males and females.

\subsubsection{Error (Co)variance Invariance}

The next step was to evaluate the residual variance invariance by constraining the residual variances of the indicators to be equal across gender. As before, the chi-square difference test was not significant $\left(\Delta \chi_{(21)}^{2}=\right.$ 26.626, $p=0.184$ ). This suggests that the indicator residual variances are invariant across gender so comparisons of observed co (variances) are interpretable. It also indicates that strict factorial invariance hold for males and females.

\subsubsection{Latent Variance \& Covariance Invariance}

The measurement invariance of the job satisfaction has been fully evaluated at this point. The next step is to evaluate structural invariance in the latent variance which is meaningful to compare the factor variance across gender. To assess factor variance invariance, the factor variance in the female was constrained to be equal to the factor variance in the male group. The chi-square difference test was significant $\left(\Delta \chi_{(15)}^{2}=18.254, p=0.250\right)$. This indicates that the factor variance was invariant across gender or homogeneity of variance across gender hold.

\subsubsection{Latent Mean Comparison}

The structural invariance in the latent mean is important to compare the latent mean across gender. There was a significant difference in the PD between males and females, with females exhibiting higher levels than males, $B$ $=0.384, p=0.010$. Other factors of IR, RE, WN, and WE were not statistically significant at the level 0.05 ( $p=$ $0.452 ; 0.125 ; 0.188 ; 0.073$, respectively). Therefore, there were no differences in the factor IR, RE, WN, and WE between males and females.

Table 4. Model fit indices for evaluating measurement invariance for the job satisfaction

\begin{tabular}{lccccccc}
\hline & $\chi^{2}(d f)$ & $P$ & CFI & RMSEA & WRMR & $\Delta \chi^{2}(\Delta d f)^{a}$ & $p$ \\
\hline Configural & $452.178(358)$ & $<0.001$ & 0.970 & 0.036 & 1.268 & - & - \\
Loading and Intercept/Treshold & $464.411(369)$ & $<0.001$ & 0.970 & 0.035 & 1.294 & $14.736(11)$ & 0.195 \\
Error Variance & $485.615(390)$ & $<0.001$ & 0.970 & 0.034 & 1.358 & $26.626(21)$ & 0.184 \\
Latent Variance\& Covariance & $489.189(405)$ & 0.003 & 0.973 & 0.032 & 1.463 & $18.254(15)$ & 0.250 \\
\hline
\end{tabular}

Note. ${ }^{\mathrm{a} C a l c u l a t i o n s}$ based on DIFFTEST command.

All indicators were statistically significant at the level 0.05 with the exception the wrksped and monoton indicators for the $\mathrm{WN}$ factor. The factor loadings for each indicator were shown in Table 5. 
Table 5. Estimates for the multiple groups model of the job satisfaction

\begin{tabular}{|c|c|c|c|c|c|c|c|c|c|}
\hline \multirow{2}{*}{ Indicators } & \multirow{2}{*}{ Factors } & \multirow{2}{*}{$\begin{array}{c}\text { Standardized } \\
\text { Estimate }\end{array}$} & \multicolumn{3}{|c|}{ Unstandardized } & \multirow{2}{*}{$\begin{array}{c}\text { Stand. } \\
\text { Tresholds }\end{array}$} & \multicolumn{3}{|c|}{ Unstandardized Tresholds } \\
\hline & & & Estimate & S.E. & $p$-value & & Estimate & S.E. & $p$-value \\
\hline Promot & PD & 0.739 & 1.000 & - & - & -0.880 & -1.307 & 0.157 & 0.000 \\
\hline Qualiwrk & & 0.658 & 0.795 & 0.183 & $<0.001$ & -0.884 & -1.174 & 0.132 & 0.000 \\
\hline Training & & 0.724 & 0.956 & 0.224 & $<0.001$ & -0.174 & -0.252 & 0.114 & 0.026 \\
\hline Ideas & & 0.801 & 1.220 & 0.313 & $<0.001$ & -0.273 & -0.456 & 0.143 & 0.001 \\
\hline Cowrks & IR & 0.497 & 1.000 & - & - & -1.405 & -1.619 & 0.140 & 0.000 \\
\hline Teamwrk & & 0.636 & 1.437 & 0.396 & $<0.001$ & -0.557 & -0.721 & 0.109 & 0.000 \\
\hline Boss & & 0.925 & 4.254 & 1.371 & 0.002 & -0.786 & -2.071 & 0.465 & 0.000 \\
\hline Equaltrt & & 0.878 & 3.206 & 0.925 & 0.001 & -0.961 & -2.010 & 0.318 & 0.000 \\
\hline Commun & & 0.882 & 3.257 & 0.968 & 0.001 & -0.908 & -1.923 & 0.314 & 0.000 \\
\hline Salary & $\mathrm{RE}$ & 0.857 & 1.000 & - & - & -0.310 & -0.601 & 0.198 & 0.002 \\
\hline Bonus & & 0.669 & 0.541 & 0.184 & 0.003 & -1.028 & -1.383 & 0.161 & 0.000 \\
\hline Accomp & & 0.832 & 0.901 & 0.389 & 0.020 & -1.210 & -2.179 & 0.387 & 0.000 \\
\hline Steadyem & & 0.721 & 0.625 & 0.228 & 0.006 & -1.251 & -1.804 & 0.229 & 0.000 \\
\hline Wrkamont & WN & 0.928 & 1.000 & - & - & -0.502 & -1.351 & 0.588 & 0.022 \\
\hline Wrksped & & 0.872 & 0.712 & 0.467 & 0.127 & -0.795 & -1.621 & 0.379 & 0.000 \\
\hline Monoton & & -0.212 & -0.087 & 0.060 & 0.147 & 0.802 & 0.820 & 0.076 & 0.000 \\
\hline Cleanhy & WE & 0.694 & 1.000 & - & - & 0.065 & 0.090 & 0.103 & 0.381 \\
\hline Light & & 0.765 & 1.233 & 0.222 & $<0.00$ & -0.551 & -0.855 & 0.143 & 0.000 \\
\hline Venti & & 0.958 & 3.469 & 1.003 & 0.001 & -0.104 & -0.361 & 0.307 & 0.239 \\
\hline Temp & & 0.888 & 2.011 & 0.392 & $<0.001$ & -0.005 & -0.012 & 0.178 & 0.947 \\
\hline Workspace & & 0.740 & 1.143 & 0.188 & $<0.001$ & 0.017 & 0.026 & 0.113 & 0.821 \\
\hline Variances & & & & & & \multicolumn{4}{|c|}{ Means Difference Females-Males } \\
\hline PD & & 1 & 1.206 & 0.382 & 0.002 & 0.349 & 0.383 & 0.149 & 0.010 \\
\hline IR & & 1 & 0.328 & 0.157 & 0.036 & -0.094 & -0.054 & 0.072 & 0.455 \\
\hline RE & & 1 & 2.767 & 1.502 & 0.066 & 0.223 & 0.371 & 0.242 & 0.125 \\
\hline WN & & 1 & 6.234 & 5.596 & 0.265 & -0.204 & -0.509 & 0.389 & 0.191 \\
\hline WE & & 1 & 0.927 & 0.239 & 0.000 & -0.206 & -0.198 & 0.110 & 0.073 \\
\hline Covariances & & & & & & Correlations & & & \\
\hline PD with IR & & & 0.417 & 0.124 & 0.001 & PD with IR & 0.663 & 0.056 & 0.000 \\
\hline PD with RE & & & 1.086 & 0.321 & 0.001 & PD with RE & 0.595 & 0.072 & 0.000 \\
\hline PD with WN & & & 1.410 & 0.669 & 0.035 & PD with WN & 0.514 & 0.068 & 0.000 \\
\hline PD with WE & & & 0.590 & 0.143 & 0.000 & PD with WE & 0.558 & 0.060 & 0.000 \\
\hline IR with RE & & & 0.441 & 0.172 & 0.010 & IR with RE & 0.463 & 0.071 & 0.000 \\
\hline IR with WN & & & 0.494 & 0.254 & 0.052 & IR with WN & 0.345 & 0.073 & 0.000 \\
\hline IR with WE & & & 0.170 & 0.058 & 0.004 & IR with WE & 0.309 & 0.068 & 0.000 \\
\hline RE with WN & & & 1.637 & 0.878 & 0.062 & RE with WN & 0.394 & 0.079 & 0.000 \\
\hline RE with WE & & & 0.649 & 0.206 & 0.002 & RE with WE & 0.406 & 0.067 & 0.000 \\
\hline WE with WN & & & 1.000 & 0.464 & 0.031 & WE with WN & 0.416 & 0.063 & 0.000 \\
\hline
\end{tabular}

The correlation between PD and IR was estimated at 0.663 , between PD and RE at 0.595 , between PD and WN at 0.514 , and between PD and WE at 0.558. The correlation between IR and RE was estimated at 0.463 , between IR and WN at 0.345 , between IR and WE at 0.309 . The correlation between RE and WN was estimated at 0.394 , and between RE and WE at 0.406. The correlation between WN and WE was estimated at 0.416.

\subsubsection{Model Interpretations}

The estimated probability of an individual for indicator with average factor endorsing satisfied option can be determined using

$$
P\left(y_{i j}=1 \mid f_{i}, \lambda_{j}, \tau_{j}\right)=\Phi\left(-\tau_{j}+\lambda_{j} f_{i}\right)
$$

where $f_{i}$ is the $i^{t h}$ individual factor score, $\tau_{j}$ is the threshold for indicator $j, \lambda_{j}$ is the factor loading for indicator $j$, and $\Phi$ is the cumulative distribution function for the standard normal distribution.

Since there are only two options (1: satisfied and 0: dissatisfied), the estimated probability of an individual for indicator with average factor endorsing dissatisfied option is determined by 


$$
P\left(y_{i j}=0 \mid f_{i}, \lambda_{j}, \tau_{j}\right)=1-P\left(y_{i j}=1 \mid f_{i}, \lambda_{j}, \tau_{j}\right)
$$

For example, the estimated probability of an individual for indicator qualiwrk with average PD factor endorsing satisfied and dissatisfied options are

$$
\begin{gathered}
P(y=1)=\Phi((-1)(-1.174)+(0.795)(0))=\Phi(1.174)=0.880 \\
P(y=0)=1-P(y=1)=0.880=0.12
\end{gathered}
$$

Table 6 shows the probabilities for all indicators under each factor. Overall, the individual was most likely to endorse satisfied response with the exception indicator monoton on the WN factor, indicators cleanhy and workspace on the WE factor. For the PD factor, the probabilities for being satisfied in the training and ideas indicators were 0.599 and 0.676 which were lower than 0.75 . From these can be inferred that training opportunities and implementing ideas need more attention to be able to improve in the personal development perspective. For the IR factor, all probabilities are greater than 0.75 . These indicated that the interpersonal relationship is working well. For the RE factor, the probability being satisfied of $0.726(<0.75)$ for salary indicator suggested that the individual will be more satisfied if the salary is increased. For the WN factor, the probability of being satisfied for the monoton indicator had the lowest probability $(0.206)$ which yielded an alarm signal for the hospital management. For the WE factor, most indicators had probabilities that were less than 0.75 with the exception of light indicator. These suggested that there should be improvement on the clean and hygiene, ventilation, temperature, and workspace for having job satisfaction in the work environment.

Table 6. The estimated probabilities for the multiple groups model

\begin{tabular}{llll}
\hline Indicators & Factors & Probabilities of being satisfied $P(y=1)$ & Probabilities of being dissatisfied $P(y=0)$ \\
\hline Promot & & 0.904 & 0.096 \\
Qualiwrk & PD & 0.880 & 0.120 \\
Training & & 0.599 & 0.401 \\
Ideas & & 0.676 & 0.324 \\
\hline Cowrks & & 0.947 & 0.053 \\
Teamwrk & & 0.765 & 0.235 \\
Boss & IR & 0.981 & 0.019 \\
Equaltrt & & 0.978 & 0.022 \\
Commun & & 0.973 & 0.027 \\
\hline Salary & & 0.726 & 0.274 \\
Bonus & RE & 0.917 & 0.083 \\
Accomp & & 0.985 & 0.015 \\
Steadyem & & 0.964 & 0.036 \\
\hline Wrkamont & & 0.912 & 0.088 \\
Wrksped & WN & 0.947 & 0.053 \\
Monoton & & 0.206 & 0.794 \\
\hline Cleanhy & & 0.464 & 0.536 \\
Light & & 0.804 & 0.196 \\
Venti & WE & 0.641 & 0.359 \\
Temp & & 0.505 & 0.495 \\
Workspace & & 0.490 & 0.510 \\
\hline
\end{tabular}

\subsection{Multiple Indicators and Multiple Causes}

Another way to estimate group differences on the latent factors is through the MIMIC model (see Figure 3) where factors with effect indicators are regressed on one or more dichotomous cause indicators that represent group membership. The MIMIC requires assumptions of measurement invariance across the groups. It was shown in Table 4 that the measurement invariance across gender was fulfilled. Thus, the MIMIC model can be used in this project. The $\chi_{(195)}^{2}=300.008$ and $p<0.001$ was significant, which indicated a lack of exact model fit across gender. Fit indices suggest that the overall model has a good fit, CFI $=0.969>0.96$, RMSEA $=0.036<$ $0.06, \mathrm{WRMR}=0.995<1$. 


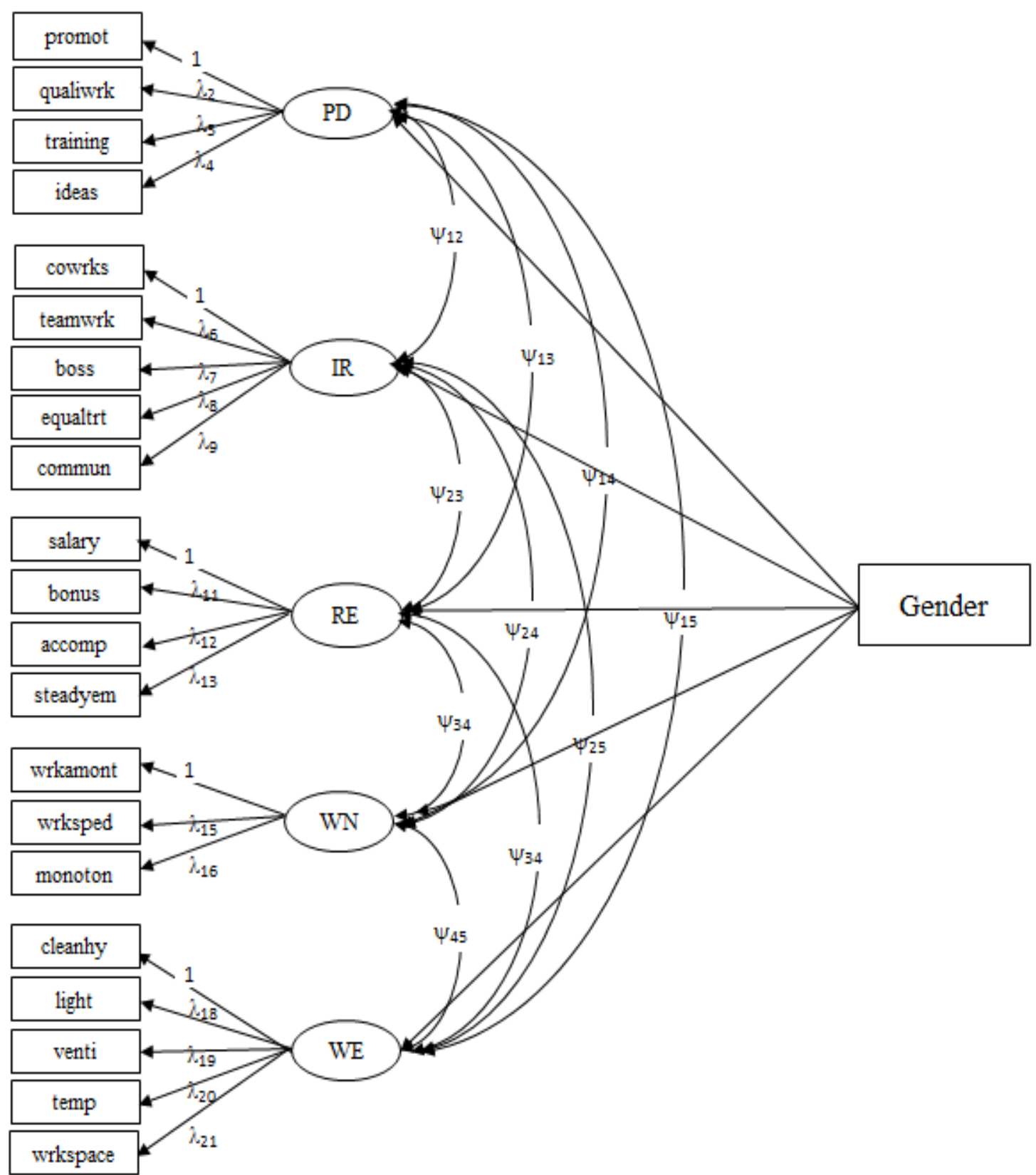

Figure 3. A path diagram of MIMIC representing the factor structure of the job satisfaction

The unstandardized coefficient of PD on female was 0.356 (S.E. $=0.138)$ with $p=0.010$, which suggested a significant difference in the PD between males and females, with females exhibiting higher levels than males. The unstandardized coefficients of IR, RE, WN, and WE are -0.053 (S.E. $=0.072$ ) with $p=0.459,0.365$ (S.E. $=$ 0.236 ) with $p=0.121,-0.455$ (S.E. $=0.332$ ) with $p=0.170,-0.198$ (S.E. $=0.110)$ with $p=0.073$, respectively. The factors IR, RE, WN, and WE were not statistically significant at the level 0.05 . These results were similar to the multiple groups analysis results.

The correlation between PD and IR was estimated at 0.671 , between PD and RE at 0.603 , between PD and WN at 0.528 , and between PD and WE at 0.547 . The correlation between IR and RE was estimated at 0.460 , between IR and WN at 0.353 , between IR and WE at 0.304 . The correlation between RE and WN was estimated at 0.387 , and between RE and WE at 0.394 . The correlation between WN and WE was estimated at 0.417 . The factor loadings for each indicator are shown in Table 7. All indicators were statistically significant at the level 0.05 with the exception the wrksped and monoton indicators for the $\mathrm{WN}$ factor. The factor loadings for each indicator were shown in Table 7. 
Table 7. Estimates for the MIMIC model of the job satisfaction

\begin{tabular}{|c|c|c|c|c|c|c|c|c|c|}
\hline \multirow{2}{*}{ Indicator } & \multirow{2}{*}{ Factor } & \multirow{2}{*}{$\begin{array}{c}\text { Standardized } \\
\text { Estimate }\end{array}$} & \multicolumn{3}{|c|}{ Unstandardized } & \multirow{2}{*}{$\begin{array}{c}\text { Std. } \\
\text { Tresholds }\end{array}$} & \multicolumn{3}{|c|}{ Unstandardized } \\
\hline & & & Estimate & S.E. & $p$-value & & Estimate & S.E. & $p$-value \\
\hline Promot & \multirow[t]{4}{*}{ PD } & 0.716 & 1.000 & - & - & -0.877 & -1.255 & 0.165 & 0.000 \\
\hline Qualiwrk & & 0.629 & 0.790 & 0.178 & 0.000 & -0.804 & -1.034 & 0.141 & 0.000 \\
\hline Training & & 0.727 & 1.034 & 0.242 & 0.000 & -0.137 & -0.200 & 0.131 & 0.127 \\
\hline Ideas & & 0.807 & 1.334 & 0.348 & 0.000 & -0.352 & -0.595 & 0.163 & 0.000 \\
\hline Cowrks & \multirow[t]{5}{*}{ IR } & 0.494 & 1.000 & - & - & -1.415 & -1.627 & 0.173 & 0.000 \\
\hline Teamwrk & & 0.620 & 1.391 & 0.384 & 0.000 & -0.67 & -0.854 & 0.133 & 0.000 \\
\hline Boss & & 0.919 & 4.094 & 1.288 & 0.001 & -0.755 & -1.912 & 0.424 & 0.000 \\
\hline Equaltrt & & 0.871 & 3.121 & 0.897 & 0.001 & -0.922 & -1.878 & 0.307 & 0.000 \\
\hline Commun & & 0.881 & 3.273 & 0.975 & 0.001 & -0.883 & -1.865 & 0.331 & 0.000 \\
\hline Salary & \multirow[t]{4}{*}{$\mathrm{RE}$} & 0.852 & 1.000 & - & - & -0.258 & -0.491 & 0.194 & 0.011 \\
\hline Bonus & & 0.670 & 0.555 & 0.187 & 0.003 & -0.961 & -1.295 & 0.179 & 0.000 \\
\hline Accomp & & 0.829 & 0.911 & 0.390 & 0.019 & -1.221 & -2.182 & 0.410 & 0.000 \\
\hline Steadyem & & 0.709 & 0.618 & 0.222 & 0.005 & -1.447 & -2.051 & 0.282 & 0.000 \\
\hline Wrkamont & \multirow[t]{3}{*}{ WN } & 0.911 & 1.000 & 0.000 & - & -0.604 & -1.461 & 0.518 & 0.005 \\
\hline Wrksped & & 0.855 & 0.749 & 0.420 & 0.075 & -0.684 & -1.321 & 0.308 & 0.000 \\
\hline Monoton & & -0.210 & -0.097 & 0.063 & 0.125 & 0.772 & 0.790 & 0.105 & 0.000 \\
\hline Cleanhy & \multirow[t]{5}{*}{ WE } & 0.695 & 1.000 & - & - & 0.072 & 0.100 & 0.126 & 0.426 \\
\hline Light & & 0.761 & 1.212 & 0.219 & 0.000 & -0.604 & -0.931 & 0.165 & 0.000 \\
\hline Venti & & 0.958 & 3.447 & 0.987 & 0.000 & -0.059 & -0.206 & 0.319 & 0.518 \\
\hline Temp & & 0.890 & 2.017 & 0.395 & 0.000 & 0.046 & 0.100 & 0.198 & 0.613 \\
\hline Workspace & & 0.740 & 1.138 & 0.190 & 0.000 & -0.059 & -0.088 & 0.135 & 0.515 \\
\hline \multicolumn{5}{|c|}{ Residual Variances } & \multicolumn{5}{|c|}{ Latent Factors ON Females } \\
\hline & \multirow{2}{*}{$\begin{array}{c}\text { Std. } \\
\text { Estimate }\end{array}$} & \multicolumn{3}{|c|}{ Unstandardized } & Latent & \multirow{2}{*}{ Std. Estimate } & \multicolumn{3}{|c|}{ Unstandardized } \\
\hline Latent Factors & & Estimate & S.E. & $p$-value & Factors & & Estimate & S.E. & $p$-value \\
\hline $\mathrm{PD}$ & 0.970 & 1.018 & 0.320 & 0.001 & $\mathrm{PD}$ & 0.173 & 0.356 & 0.138 & 0.010 \\
\hline IR & 0.998 & 0.323 & 0.155 & 0.037 & IR & -0.047 & -0.053 & 0.072 & 0.459 \\
\hline $\mathrm{RE}$ & 0.987 & 2.609 & 1.390 & 0.061 & $\mathrm{RE}$ & 0.112 & 0.365 & 0.236 & 0.121 \\
\hline $\mathrm{WN}$ & 0.989 & 4.808 & 3.601 & 0.182 & $\mathrm{WN}$ & -0.103 & -0.455 & 0.332 & 0.170 \\
\hline WE & 0.990 & 0.926 & 0.241 & 0.000 & WE & -0.102 & -0.198 & 0.110 & 0.073 \\
\hline \multirow[t]{2}{*}{ Covariances } & & & & & \multicolumn{2}{|c|}{ Correlations } & & & \\
\hline & & Estimate & S.E. & $p$-value & & & Estimate & & \\
\hline PD with IR & & 0.385 & 0.116 & 0.001 & PD with & & 0.671 & & \\
\hline PD with RE & & 0.983 & 0.289 & 0.001 & PD with & & 0.603 & & \\
\hline PD with WN & & 1.167 & 0.480 & 0.015 & PD with & & 0.528 & & \\
\hline PD with WE & & 0.531 & 0.131 & 0.000 & PD with & & 0.547 & & \\
\hline IR with RE & & 0.422 & 0.164 & 0.010 & IR with & & 0.460 & & \\
\hline IR with WN & & 0.440 & 0.201 & 0.029 & IR with & & 0.353 & & \\
\hline IR with WE & & 0.166 & 0.058 & 0.004 & IR with & & 0.304 & & \\
\hline RE with WN & & 1.372 & 0.649 & 0.035 & RE with & & 0.387 & & \\
\hline RE with WE & & 0.613 & 0.195 & 0.002 & RE with & & 0.394 & & \\
\hline WN with WE & & 0.880 & 0.354 & 0.013 & WN wit & & 0.417 & & \\
\hline
\end{tabular}

Model Interpretations. Table 8 shows the probabilities for all indicators under each factor. The probabilities of being satisfied from MIMIC model are similar with the probabilities of being satisfied from the multiple groups model. Also, the interpretations remain the same as above. 
Table 8. The estimated probabilities for the MIMIC model

\begin{tabular}{llll}
\hline Indicators & Factors & Probabilities of being satisfied $P(y=1)$ & Probabilities of being dissatisfied $P(y=0)$ \\
\hline Promot & & 0.895 & 0.105 \\
Qualiwrk & PD & 0.849 & 0.151 \\
Training & & 0.579 & 0.421 \\
Ideas & 0.724 & 0.276 \\
\hline Cowrks & 0.948 & 0.052 \\
Teamwrk & & 0.803 & 0.197 \\
Boss & IR & 0.972 & 0.028 \\
Equaltrt & & 0.970 & 0.030 \\
Commun & & 0.969 & 0.031 \\
\hline Salary & & 0.688 & 0.312 \\
Bonus & 0.902 & 0.098 \\
Accomp & RE & 0.985 & 0.015 \\
Steadyem & & 0.980 & 0.020 \\
\hline Wrkamont & & 0.928 & 0.072 \\
Wrksped & WN & 0.907 & 0.093 \\
Monoton & & 0.215 & 0.785 \\
\hline Cleanhy & & 0.460 & 0.540 \\
Light & & 0.824 & 0.176 \\
Venti & WE & 0.582 & 0.418 \\
Temp & & 0.460 & 0.540 \\
Workspace & & 0.535 & 0.465 \\
\hline & & &
\end{tabular}

\section{Conclusions}

In the analysis we have presented a set of plausible measurement models for examining five factors of job satisfaction: personal development, interpersonal relationship, recognition, work nature and work environment. We used WLSMV estimation to evaluate the measurement models in consequence of the categorical indicators. For computational reason, probit link was chosen rather than logit link because both links yielded same results. By neglecting gender, the CFA model yielded four factors which described well the job satisfaction. These results were supported by all indicators for personal development, interpersonal relationship, recognition and work environment that were statistically significant and all indicators for work nature that were not significant. The results of correlations between factors indicated the existence of mild and strong relationship between the factors.

The interpersonal relationship factor is the only factor which has higher probability of being satisfied for each indicator. This indicates the interpersonal relationship was working well. Others factors have at least one indicator shows lower probability. The lower probability informs a signal improvement. In the personal development factor was found that training opportunities and implementing ideas should become more attention to be improved. In the recognition factor was obtained that the individual will be more satisfied if the salary can be increased. In the work nature, the monotone yielded highly alarm signal to be serious attention. In the work environment was found that most indicators (clean and hygiene, ventilation, temperature, and workspace) with the exception light need to be improved.

We confirmed a dichotomous instrument of 21 items and five factors to measure job satisfaction in a Mexican hospital and also we shown evidence that the same construct is appropriate for both male and female with the exception that female presented higher levels of satisfaction in their job for the personal development. However, it is important to point out that these results apply to only to the General Hospital number 1, located in the State of Colima, Mexico, since the sample only is representative to this hospital. Also, as one reviewer suggested maybe it should be better to use a five or seven Likert scale in a future research since some of the questions in the proposed instrument do not share a common referent (as I have an opportunity to be promoted, I am satisfied with the quality of work) to improve the instrument and our understanding of the levels of satisfaction in Hospitals and organizations.

Finally it is important to point out that more research is required to be able to generalize these results to all the hospitals of the IMSS in Mexico. Also it should be very interesting to verifying measurement invariance between doctors, nurses and administrative staff. Which was no done here since the group of doctors has a smaller sample 
size.

\section{References}

Bender, K., Donohue, S., \& Heywood, J. (2005). Job satisfaction and gender segregation. Oxford Economic Papers, 57(3), 479-496. http://dx.doi.org/10.1093/oep/gpi015

Bosch, T., Mathiassen, S. E., Visser, B., De Looze, M. P., \& Van Dieën, J. H. (2011). The effect of work pace on workload, motor variability and fatigue during simulated light assembly work. Ergonomics, 54(2), 154-168. http://dx.doi.org/10.1080/00140139.2010.538723

Bovaird, J. A., \& Koziol, N. A. (2012). Measurement models for ordered categorical indicators in structural equation modeling. In R. H. Hoyle, D. Kaplan, Marcoulides, \& S. West (Eds.), Handbook of structural equation modeling. New York, NY: The Guilford Press.

Browne, M. W., \& Cudeck, R. (1993). Alternative ways of assessing model fit. In Bollen, K. A., \& Long, J. S. (Eds.), Testing Structural Equation Models (pp. 136-162). Beverly Hills, CA: Sage. http://dx.doi.org/10.1177/0049124192021002005

Danish, R. Q., \& Usman, A. (2010). Impact of reward and recognition on job satisfaction and motivation: an empirical study from pakistan. International Journal of Business and Management, 159-167.

Donovan, M. A., Drasgow, F., \& Munson, L. J. (1998). The perceptions of fair interpersonal treatment scale: Development and validation of a measure of interpersonal treatment in the workplace. Journal of Applied Psychology, 83, 683-692. http://dx.doi.org/10.1037/0021-9010.83.5.683

Hackman, J. R., \& Oldham, G. R. (1975). Development of job diagnostic survey. Journal of Applied Psychology, 60, 159-170.

Hu \& Bentler. (1999). Cutoff criteria for fit indexes in covariance structure analysis: Conventional criteria versus new alternatives. Structural Equation $\quad$ Modeling, $\quad 6(1), \quad 1-55$. http://dx.doi.org/10.1080/10705519909540118

Infante, C. C. (2006). Quejas médicas. Insatisfacción de los pacientes con respecto a la calidad de la atención médica. México: ETM.

Instituto Mexicano del Seguro Social. (2011). Memorias Estadísticas 2011. México: IMSS.

Instituto Mexicano del Seguro Social. (2012a). Informe de Servicios Personales2012. México: IMSS.

Instituto Mexicano del Seguro Social. (2012b). Publicación "60 Años de Servir a México" y Acervo Documental Secretaría General. México: IMSS.

Kaiser, L. C. (2002). Job satisfaction: A comparison of standard, non-standard, and self-employment patterns across Europe with a special note to the gender/job satisfaction paradox. EPAG Working Paper 27, Colchester, University of Essex. Retrieved from http://www.iser.essex.ac.uk/epag/pubs/workpaps/pdf/2002-27.pdf

Kline, R. B. (2011). Principles and practice structural equation modeling. New York, NY: The Guilford Press.

Lang, S. S. (2005). Warm offices linked to higher productivity. Human Ecology, 32(2), 23-25.

MacCallum, R. C., \& Browne, M. W. (1993). The use of causal indicators in covariance structure models: Some practical issues. Psychological Bulletin, 114, 533-541. http://dx.doi.org/10.1037/0033-2909.114.3.533

Martín, G. (2011). Noroeste Grupo Editorial. Muestran insatisfacción por atención del IMSS. Rechazan derechohabientes resultados de encuesta sobre satisfacción. Retrieved from http://www.noroeste.com.mx/publicaciones.php?id=692013

Maslow, A. H. (1970). Motivation and Personality. New York: Harper \& Row.

Roberto, G. (2014). Tiene IMSS la mayoría de quejas por mal servicio. Retrieved from http://am.com.mx/leon/local/tiene-imss-la-mayoria-de-quejas-por-mal-servicio-98160.html

Ruth, R. (2013). El universal. IMSS encabeza quejas; firma pacto con CNDH. Retrieved from http://www.eluniversal.com.mx/nacion/207240.html

Spector, P. E. (1985). Measurement of human service staff satisfaction: Development of the Job Satisfaction Survey. American Journal of Community Psychology, 13(6), 693-713. http://dx.doi.org/10.1007/BF00929796

Spector, P. E. (1997). Job satisfaction: Application, assessment, causes, and consequences. Thousand Oaks, CA: 
Sage.

Yu, C. Y., \& Muthen, B. (2002). Evaluation of model fit indices for latent variable models with categorical and continuous outcomes (Technical report). Los Angeles, CA: University of California at Los Angeles, Graduate School of Education \& Information Studies.

\section{Appendix A}

M-plus code for the path diagram of CFA representing the factors structure of the job satisfaction given in Figure 1

TITLE: Confirmatory Factor Analysis_Model 1;

DATA: FILE = job.txt;

\section{VARIABLE:}

NAMES $=$ obs female promot qualiwrk

training ideas respons cowrks teamwrk boss

equaltrt commun salary bonus accomp steadyem

monoton wrkamont wrksped cleanhy

light venti temp wrkspace;

USEVARIABLES = promot-wrkspace;

CATEGORICAL = promot-wrkspace;

MISSING $=$;

ANALYSIS:

ESTIMATOR = WLSMV;

PARAMETERIZATION $=$ THETA;

PROCESSORS $=8$;

ITERATION=100000;

MODEL:

!Measurement model

PD by promot@1 qualiwrk training ideas;PD*;

IR by cowrks@1 teamwrk boss equaltrt commun;IR*;

RE by salary@1 bonus accomp steadyem;RE*;

WN by wrkamont@1 wrksped monoton;WN*;

WE by cleanhy@1 light venti temp wrkspace;WE*;

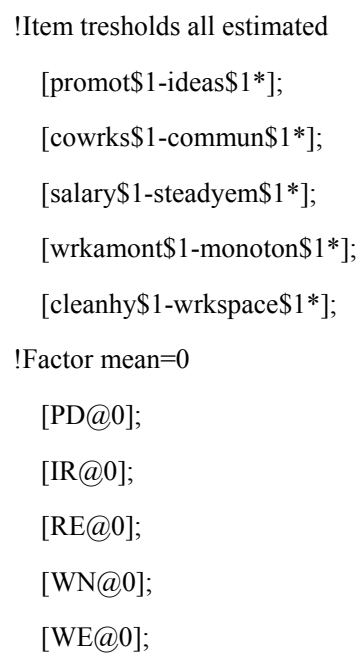




\section{OUTPUT: SAMPSTAT STDYX MOD;}

\section{Appendix B}

M-plus code for the path diagram of two groups (male and female) representing the factor structure of the job satisfaction given in Figure 2

\section{Configural Invariance}

TITLE: Multiple Groups Model 2 Configural Invariance;

DATA: FILE $=$ job.txt;

\section{VARIABLE:}

NAMES $=$ obs female promot qualiwrk

training ideas respons cowrks teamwrk boss

equaltrt commun salary bonus accomp steadyem

monoton wrkamont wrksped cleanhy

light venti temp wrkspace;

USEVARIABLES = promot-wrkspace;

CATEGORICAL = promot-wrkspace;

MISSING $=$;

ANALYSIS:

ESTIMATOR $=$ WLSMV;

PARAMETERIZATION $=$ THETA;

PROCESSORS $=8$;

ITERATION=100000;

MODEL:

!!!!Configural Invariance

!Model for males

PD by promot@1

qualiwrk training ideas (L2-L4);

[promot\$1-ideas\$1*] (Ia1-Ia4);

promot-ideas@1 (R1-R4);

PD* (V1);

[PD@0] (M1);

IR by cowrks@1

teamwrk boss equaltrt commun (L6-L9);

[cowrks\$1-commun\$1*] (Ia5-Ia9);

cowrks-commun@1 (R5-R9);

IR* (V2);

[IR@0] (M2);

RE by salary@1

bonus accomp steadyem (L11-L13);

[salary\$1-steadyem\$1*] (Ia10-Ia13);

salary-steadyem@1 (R10-R13);

RE* (V3);

[RE@0] (M3);

WN by wrkamont@1 


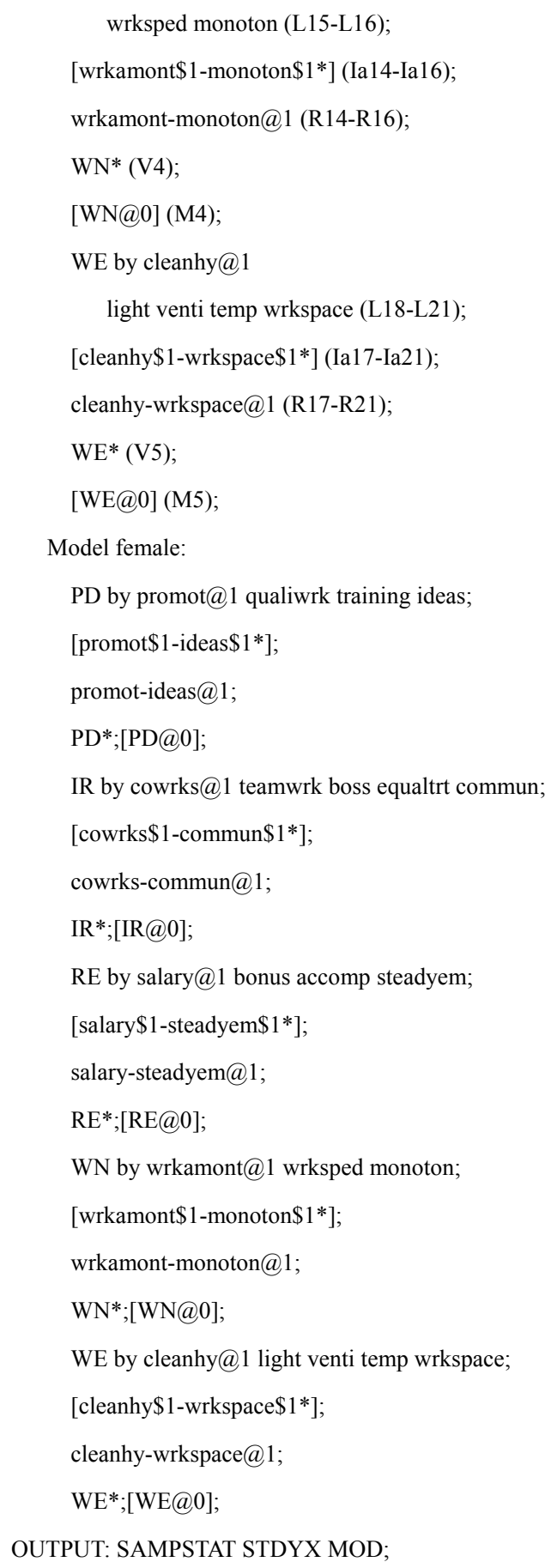

SAVEDATA: DIFFTEST=ConfiguralModel_Derivatives.dat;

\section{Loading and Intercept/Threshold Invariance}

TITLE: Multiple Groups Model 2 Loading and Intercept or Threshold Invariance;

DATA: FILE = job.txt;

VARIABLE:

NAMES $=$ obs female promot qualiwrk training ideas respons cowrks teamwrk boss equaltrt commun salary bonus accomp steadyem monoton wrkamont wrksped cleanhy 
light venti temp wrkspace;

USEVARIABLES = promot-wrkspace;

CATEGORICAL = promot-wrkspace;

MISSING $=$;

ANALYSIS:

ESTIMATOR = WLSMV;

PARAMETERIZATION = THETA;

PROCESSORS $=8$;

ITERATION=100000;

MODEL:

!!!!!!!!!!!! Loading and Intercept/Treshold Invariance

!Model for males

PD by promot@1

qualiwrk training ideas (L2-L4);

[promot\$1-ideas\$1*] (Ia1-Ia4);

promot-ideas@1 (R1-R4);

PD* (V1);

[PD@0] (M1);

IR by cowrks@1

teamwrk boss equaltrt commun (L6-L9);

[cowrks\$1-commun\$1*] (Ia5-Ia9);

cowrks-commun@1 (R5-R9);

IR* (V2);

[IR@0] (M2);

RE by salary@1

bonus accomp steadyem (L11-L13);

[salary\$1-steadyem $\$ 1 *$ ] (Ia10-Ia13);

salary-steadyem@1 (R10-R13);

RE* (V3);

[RE@0] (M3);

WN by wrkamont@1

wrksped monoton (L15-L16);

[wrkamont\$1-monoton\$1*] (Ia14-Ia16);

wrkamont-monoton@1 (R14-R16);

$\mathrm{WN}^{*}(\mathrm{~V} 4)$;

[WN@0] (M4);

WE by cleanhy@1

light venti temp wrkspace (L18-L21);

[cleanhy\$1-wrkspace\$1*] (Ia17-Ia21);

cleanhy-wrkspace@1 (R17-R21);

WE* (V5);

[WE@0] (M5); 
Model female:

PD by promot@ 1

qualiwrk training ideas (L2-L4);

[promot\$1-ideas\$1*] (Ia1-Ia4);

promot-ideas*;

$\mathrm{PD}^{*} ;\left[\mathrm{PD}^{*}\right]$;

IR by cowrks@1

teamwrk boss equaltrt commun (L6-L9);

[cowrks\$1-commun\$1*] (Ia5-Ia9);

cowrks-commun*;

$\mathrm{IR}^{*} ;\left[\mathrm{IR}^{*}\right]$;

RE by salary@1

bonus accomp steadyem (L11-L13);

[salary $\$ 1$-steadyem $\$ 1 *$ ] (Ia10-Ia13);

salary-steadyem*;

$\mathrm{RE}^{*} ;\left[\mathrm{RE}^{*}\right]$;

WN bywrkamont@1

wrksped monoton (L15-L16);

[wrkamont\$1-monoton\$1*] (Ia14-Ia16);

wrkamont-monoton*;

$\mathrm{WN}^{*}$;[WN*];

WE by cleanhy@1

light venti temp wrkspace (L18-L21);

[cleanhy \$1-wrkspace\$1*] (Ia17-Ia21);

cleanhy-wrkspace*;

WE*;[WE*];

OUTPUT: SAMPSTAT STDYX MOD;

SAVEDATA: DIFFTEST=LoadingTreshold_Derivatives.dat;

\section{Error (Co) variance Invariance}

TITLE: Multiple Groups Model 2 Error (Co) variance Invariance;

DATA: FILE = job.txt;

\section{VARIABLE:}

NAMES $=$ obs female promot qualiwrk

training ideas respons cowrks teamwrk boss

equaltrt commun salary bonus accomp steadyem

monoton wrkamont wrksped cleanhy

light venti temp wrkspace;

USEVARIABLES = promot-wrkspace;

CATEGORICAL = promot-wrkspace;

MISSING $=$;

ANALYSIS:

ESTIMATOR = WLSMV; 
PARAMETERIZATION $=$ THETA;

PROCESSORS $=8$;

ITERATION=100000;

MODEL:

!!!!!!!! Error (Co)variance Invariance

!Model for males

PD by promot@1

qualiwrk training ideas (L2-L4);

[promot\$1-ideas\$1*] (Ia1-Ia4);

promot-ideas@1 (R1-R4);

PD* (V1);

[PD@0] (M1);

IR by cowrks@1

teamwrk boss equaltrt commun (L6-L9);

[cowrks\$1-commun\$1*] (Ia5-Ia9);

cowrks-commun@1 (R5-R9);

IR* (V2);

[IR@0] (M2);

RE by salary@1

bonus accomp steadyem (L11-L13);

[salary $\$ 1$-steadyem $\$ 1 *$ ] (Ia10-Ia13);

salary-steadyem@1 (R10-R13);

RE* (V3);

[RE@0] (M3);

WN by wrkamont@1

wrksped monoton (L15-L16);

[wrkamont\$1-monoton\$1*] (Ia14-Ia16);

wrkamont-monoton@1 (R14-R16);

WN* (V4);

[WN@0] (M4);

WE by cleanhy@1

light venti temp wrkspace (L18-L21);

[cleanhy \$1-wrkspace\$1*] (Ia17-Ia21);

cleanhy-wrkspace@1 (R17-R21);

WE* (V5);

[WE@0] (M5);

Model female:

PD by promot@1

qualiwrk training ideas (L2-L4);

[promot\$1-ideas\$1*] (Ia1-Ia4);

promot-ideas@1 (R1-R4);

$\mathrm{PD}^{*} ;\left[\mathrm{PD}^{*}\right]$; 
IR by cowrks@1

teamwrk boss equaltrt commun (L6-L9);

[cowrks\$1-commun\$1*] (Ia5-Ia9);

cowrks-commun@1 (R5-R9);

$\mathrm{IR}^{*} ;\left[\mathrm{IR}^{*}\right]$;

RE by salary@1

bonus accomp steadyem (L11-L13);

[salary $\$ 1$-steadyem $\$ 1^{*}$ ] (Ia10-Ia13);

salary-steadyem@1 (R10-R13);

$\mathrm{RE}^{*} ;\left[\mathrm{RE}^{*}\right]$;

WN by wrkamont@1

wrksped monoton (L15-L16);

[wrkamont\$1-monoton\$1*] (Ia14-Ia16);

wrkamont-monoton@1 (R14-R16);

$\mathrm{WN}^{*} ;\left[\mathrm{WN}^{*}\right]$;

WE by cleanhy@1

light venti temp wrkspace (L18-L21);

[cleanhy $\$ 1$-wrkspace\$1*] (Ia17-Ia21);

cleanhy-wrkspace@1 (R17-R21);

WE*;[WE*];

OUTPUT: SAMPSTAT STDYX MOD;

SAVEDATA: DIFFTEST=ErrorCovariance_Derivatives.dat;

\section{Latent variance structural invariance}

TITLE: Multiple Groups Model 2 Latent Variance Structural Invariance;

DATA: FILE = job.txt;

\section{VARIABLE:}

NAMES $=$ obs female promot qualiwrk

training ideas respons cowrks teamwrk boss

equaltrt commun salary bonus accomp steadyem

monoton wrkamont wrksped cleanhy

light venti temp wrkspace;

USEVARIABLES = promot-wrkspace;

CATEGORICAL = promot-wrkspace;

MISSING = ;

ANALYSIS:

ESTIMATOR = WLSMV;

PARAMETERIZATION = THETA;

PROCESSORS $=8$;

MODEL:

!!!! Latent Variance Structural

!Model for males

PD by promot@1 
qualiwrk training ideas (L2-L4);

[promot\$1-ideas\$1*] (Ia1-Ia4);

promot-ideas@1 (R1-R4);

PD* (V1);

[PD@0] (M1);

IR by cowrks@1

teamwrk boss equaltrt commun (L6-L9);

[cowrks\$1-commun\$1*] (Ia5-Ia9);

cowrks-commun@1 (R5-R9);

IR* (V2);

[IR@0] (M2);

RE by salary@1

bonus accomp steadyem (L11-L13);

[salary\$1-steadyem\$1*] (Ia10-Ia13);

salary-steadyem@1 (R10-R13);

RE* (V3);

[RE@0] (M3);

WN by wrkamont@1

wrksped monoton (L15-L16);

[wrkamont\$1-monoton\$1*] (Ia14-Ia16);

wrkamont-monoton@1 (R14-R16);

WN* (V4);

[WN@0] (M4);

WE by cleanhy@1

light venti temp wrkspace (L18-L21);

[cleanhy \$1-wrkspace\$1*] (Ia17-Ia21);

cleanhy-wrkspace@1 (R17-R21);

WE* (V5);

[WE@0] (M5);

PD WITH IR* (C1);

PD WITH RE* (C2);

PD WITH WN* (C3);

PD WITH WE* (C4);

IR WITH RE* (C5);

IR WITH WN* (C6);

IR WITH WE* (C7);

RE WITH WN* (C8);

RE WITH WE* (C9);

WN WITH WE* (C10);

Model female:

PD by promot@1

qualiwrk training ideas (L2-L4); 
[promot\$1-ideas\$1*] (Ia1-Ia4);

promot-ideas@1 (R1-R4);

PD* (V1);[PD*];

IR by cowrks@1

teamwrk boss equaltrt commun (L6-L9);

[cowrks\$1-commun\$1*] (Ia5-Ia9);

cowrks-commun@1 (R5-R9);

$\mathrm{IR}^{*}(\mathrm{~V} 2) ;\left[\mathrm{IR}^{*}\right]$;

RE by salary@1

bonus accomp steadyem (L11-L13);

[salary $\$ 1$-steadyem \$1*] (Ia10-Ia13);

salary-steadyem@1 (R10-R13);

RE* (V3);[RE*];

WN by wrkamont@1

wrksped monoton (L15-L16);

[wrkamont\$1-monoton\$1*] (Ia14-Ia16);

wrkamont-monoton@1 (R14-R16);

$\mathrm{WN}^{*}$ (V4);[WN*];

WE by cleanhy@1

light venti temp wrkspace (L18-L21);

[cleanhy\$1-wrkspace\$1*] (Ia17-Ia21);

cleanhy-wrkspace@1 (R17-R21);

WE* (V5); [WE*];

PD WITH IR* (C1);

PD WITH RE* (C2);

PD WITH WN* (C3);

PD WITH WE* (C4);

IR WITH RE* (C5);

IR WITH WN* (C6);

IR WITH WE* (C7);

RE WITH WN* (C8);

RE WITH WE* (C9);

WN WITH WE* (C10);

OUTPUT: SAMPSTAT STDYX MOD;

SAVEDATA: DIFFTEST=LatentVariance_Derivatives.dat;

Appendix C

M-plus code for the path diagram of MIMIC representing the factor structure of the job satisfaction given in Figure 3

TITLE: MIMIC Model 3;

DATA: FILE = job.txt;

VARIABLE:

NAMES $=$ obs female promot qualiwrk

training ideas respons cowrks teamwrk boss 
equaltrt commun salary bonus accomp steadyem

monoton wrkamont wrksped cleanhy

light venti temp wrkspace;

USEVARIABLES = promot-wrkspace;

CATEGORICAL $=$ promot-wrkspace;

MISSING $=$;

ANALYSIS:

ESTIMATOR $=$ WLSMV;

PARAMETERIZATION $=$ THETA;

PROCESSORS $=8$;

ITERATION=100000;

MODEL:

!Factor loadings

PD by promot@1 qualiwrk training ideas;PD*;

IR by cowrks@1 teamwrk boss equaltrt commun;IR*;

RE by salary@1 bonus accomp steadyem;RE*;

WN by wrkamont@1 wrksped monoton;WN*;

WE by cleanhy@1 light venti temp wrkspace;WE*;

PD IR RE WN WE ON female*;

!Item tresholds all estimated

[promot\$1-ideas\$1*];

[cowrks\$1-commun $\$ 1 *$;

[salary $\$ 1$-steadyem $\$ 1 *$;

[wrkamont $\$ 1$-monoton $\$ 1^{*}$ ];

[cleanhy\$1-wrkspace\$1*];

!Factor mean $=0$

[PD@0];

[IR@0];

[RE@0];

[WN@0];

[WE@0];

OUTPUT: SAMPSTAT STDYX MOD;

\section{Copyrights}

Copyright for this article is retained by the author(s), with first publication rights granted to the journal.

This is an open-access article distributed under the terms and conditions of the Creative Commons Attribution license (http://creativecommons.org/licenses/by/3.0/). 